\title{
DRONIFICAÇÃO DO PODER, VIOLÊNCIA E DADOS PESSOAIS: REGULAÇÃO DOS DRONES NA ERA DA "NORMALIZAÇÃO DO IMPENSÁVEL”
}

\author{
DRONIFICATION OF POWER, VIOLENCE AND PERSONAL DATA: \\ DRONE REGULATION IN THE AGE OF THE "NORMALIZATION OF THE UNTHINKABLE"
}

\begin{abstract}
Mateus de Oliveira Fornasier
Professor do Programa de Pós-Graduação Stricto Sensu (Mestrado e Doutorado) em Direito da Universidade Regional do Noroeste do Estado do Rio Grande do Sul (UNIJUI). Doutor em Direito pela Universidade do Vale do Rio dos Sinos (UNISINOS), com pós-doutorado em Direito pela University of Westminster (Reino Unido). mateus.fornasier@unijui.edu.br

Norberto Milton Paiva Knebel

Mestre em Direito pelo Centro Universitário La Salle (UNILASALLE). Doutorando pelo Programa de Pós-Graduação Stricto Sensu em Direito da Universidade Regional do Noroestedo Estado do Rio Grande do Sul (UNIJUI). Bolsista da Coordenação de Aperfeiçoamento dePessoal de Nível Superior, CAPES, Brasil. norberto.knebel@gmail.com

Fernanda Viero da Silva

Bolsista de iniciação científica do Programa PIBIC/CNPq. Acadêmica do Curso de Direito da Universidade Regional do Noroeste do Estado do Rio Grande do Sul (UNIJUI). fefeviero@gmail.com
\end{abstract}

\begin{abstract}
Resumo: Este artigo analisa a regulação dos drones da perspectiva da dronificação do poder. Contextualiza a dronificação do poder, buscando associar o desenvolvimento tecnológico militar e a ideologia que carrega com a tecnologia urbana de uso doméstico; e confronta a literatura da dronificação do poder com a realidade da regulação, buscando (des)continuidades frente a um novo paradigma regulatório. Como resultados, apresenta-se, inicialmente, que a regulação atual do uso de drones no Brasil está defasada frente à ubiquidade do tratamento de dados digitais, coletados massivamente pelos drones, que operam autonomamente e analisam dados oriundos de outros objetos em tempo real. Também tem-se que uma regulação adequada deve disciplinar as empresas que que desenvolvem essas tecnologias, de modo não meramente proibitivo - sendo a auditabilidade social uma alternativa para a adesão, por parte de tais empresas, a práticas em conformidade com a proteção à privacidade. $\mathrm{O}$ artigo foi escrito com o uso do método de procedimento dialético, com abordagem qualitativa e técnica de pesquisa bibliográfica e documental.
\end{abstract}

Palavras-chave: Drones. Dronificação do poder. Violência. Dados pessoais. Regulação.

Abstract: This article analyzes the regulation of drones from the perspective of the dronification of power. It contextualizes the dronification of power, seeking military technological development and an ideology that carries urban technology for domestic use; and confront a literature on the dronification of power with the reality of control, seeking (dis)continuities in the face of a new regulatory paradigm. As its results, it may be firstly presented that the current regulation of drones use in Brazil is lagging behind the ubiquity of digital data processing, which are massively collected by drones, which operate automatically and analyze data from other objects in real time. It must also be said that an adequate regulation should discipline informational companies that develop such technologies, in a way that is should not be merely prohibitive - being social audit a good alternative for companies adhering to practices in conformity with privacy policies. The article was written using the dialectical procedure method, with a qualitative approach and bibliographic-documental research technique.

Keywords: Drones. Dronification of power. Violence. Personal data. Regulation.

\section{Para citar este artigo}

ABNT NBR 6023:2018

FORNASIER, Mateus de Oliveira; KNEBEL, Norberto Milton Paiva; SILVA, Fernanda Viero da. Dronificação do poder, violência e dados pessoais: regulação dos drones na era da "normalização do impensável". Prisma Jurídico, São Paulo, v. 19, n. 1, p. 76-94, jan./jun. 2020. http://doi.org/10.5585/prismaj.v19n1.16828. 


\section{Introdução}

No dia 02 de janeiro de 2020, um bombardeio em Bagdá autorizado pelo presidente dos Estados Unidos, Donald Trump, matou um dos homens mais poderosos do Irã, seu principal general, Qassem Soleimani (DILANIAN; KUBE, 2020). Também pereceu, no ataque, dentre outras pessoas, Abu Mahdi al-Muhandis, chefe de milícia iraquiana apoiada pelos iranianos (DOUCET, 2020). Mais tarde, naquele mesmo dia, a mídia divulgou que a operação foi realizada com o auxílio de um drone, o qual, não muito surpreendentemente, era o mais letal da frota norte americana. A aeronave não tripulada MQ-9 Reaper é capaz de voar por até 27 horas a uma velocidade de cerca de $400 \mathrm{~km} / \mathrm{h}$ (G1, 2020). Em nota oficial, horas após o ataque, os Estados Unidos culpou o general Soleimani por mortes de americanos no Oriente Médio e afirmou que o objetivo do ataque foi deter planos de futuros ataques vindos de iranianos; o bombardeio em questão, com o drone, ocorreu no Aeroporto Internacional de Bagdá. Esse fato, por si só, demonstra que a geopolítica está passando por uma transição importante no exercício do poder.

Por definição da Agência Europeia de Segurança na Aviação (EASA), drones são aeronaves sem piloto a bordo. Também são denominados, tecnicamente, UAV (Unmanned Aerial Vehicle), UAS (Unmanned Aerial System), UCAV (Unmanned Combat Aerial Vehicle), RPA (Remotely Piloted Aircraft), RPAS (Remotely Piloted Aircraft System) (MIGUEL MOLINA; SEGARRA ÕNA, 2018, p. 8), VANT (veículo aéreo não tripulado) e VARP (veículo aéreo remotamente pilotado). Nessas definições encontram-se algumas distinções: há drones militares (que servem a propósitos bélicos), e há drones civis ou domésticos. Para fins deste trabalho, todavia, os drones são vistos como uma tecnologia de aplicação variada, mas que alia desenvolvimentos militar e privado em uma única e complexa forma de exercício do poder — de matar e vigiar à distância.

Entre a ampla utilização dessa tecnologia para fazer guerra e o uso doméstico há um entrelace no âmbito do desenvolvimento tecnológico que sustenta um processo de tornar os drones um símbolo do exercício do poder global - uma tecnologia que serve ao imperialismo e ao capital, ao zerar os riscos de violência em guerras para o agressor, mas que expropria dados pessoais na vida urbana, caracterizando um alinhamento com o poder das corporações digitais (as chamadas big techs). A violência perpetrada pelos drones possui característica sistêmica, da indiferença às mortes à indiferença à privacidade da população excedente, e que fornece mais-valia comportamental para o lucro daqueles sobre quem os dados são gerados. Conforme apontam Machado e Fujita (2018), talvez o principal impacto jurídico da inserção 
massiva das tecnologias de informação e comunicação tenha sido o direito à privacidade, comprometida exposta cada vez mais, exigindo novos mecanismos de proteção. A combinação entre as mais variadas tecnologias, ademais, permite a circulação imediata de dados (FELTEN, 2017).

A multiplicação das aplicações que envolvem os drones domésticos/civis corresponde e reflete o seu papel na sociedade informacional - e um exemplo disso é seu impacto na chamada economia criativa pela tomada de imagens (VERMEIREN et al., 2018, p. 126), na agricultura de precisão pelo referenciamento aéreo (RAJ et al., 2019), no comércio/consumo pelas entregas rápidas e autônomas (ULMER; THOMAS, 2018) e na segurança privada (KIM; SEO, 2017). Portanto, cada vez mais essa tecnologia faz parte dos cotidianos pessoais, em aplicações que vão desde os trabalhos mais técnicos até o uso recreativo.

O regime atual de regulação dos drones domésticos é dividido entre as normas relativas à aviação e as relativas aos direitos ambientais e garantias civis. A maior preocupação concernente a este trabalho se dá em relação ao segundo tipo, principalmente que tange aos dilemas éticos do uso dessa tecnologias nos mais variados setores - e nesse aspecto, o tema central é delimitado à privacidade e à proteção dos dados pessoais. Nesse, questiona-se, como problema de pesquisa, se esse regime é compatível com a realidade da evolução dessa tecnologia. A hipótese norteadora indica que não, sendo preciso contemplar um regime de regulação mais abrangente e que compreenda o fenômeno de maneira mais complexas, ligada às determinações do poder das grandes corporações digitais.

O objetivo deste artigo é, portanto, estudar a regulação dos drones sob o contexto teórico da teoria da dronificação do poder. A fim de atingir tal propósito, o trabalho foi dividido em duas seções, cada qual correspondente a um objetivo específico. Primeiramente, se tratará da contextualização da dronificação do poder, buscando associar o desenvolvimento tecnológico militar e a ideologia que carrega com a tecnologia urbana de uso doméstico. $\mathrm{Na}$ segunda parte, essa literatura é confrontada com a realidade da regulação jurídica atual de tal tecnologia, e busca encontrar continuidade ou descontinuidade frente a um novo paradigma regulatório.

Metodologicamente, esta pesquisa tem natureza exploratória, sendo o seu método de procedimento dialético, a sua abordagem qualitativa, e a sua técnica de pesquisa, bibliográfica e documental. 
FORNASIER, Mateus de Oliveira; KNEBEL, Norberto Milton Paiva; SILVA, Fernanda Viero da. Dronificação do poder, violência e dados pessoais: regulação dos drones na era da "normalização do impensável"

\section{Dronificacão do poder e violência: das guerras à domesticação}

A dronificação do poder, segundo a definiçãa de Boaventura de Sousa Santos (2018), consiste na metáfora dos drones militares como a forma na qual o poder é exercido hoje em dia: "quem mata, mata visualizando o inimigo no ecrã a muita distância e atingindo-o mediante movimentos do rato e toques do teclado [...]", o poder cada vez mais é exercido por protocolos que intermediam e "limpam" a violência dos atos. Todavia, esse poder vai além do campo militar, se alastra ao campo dos analistas e especuladores financeiros, que também colados às suas telas, manipulam números e tiram conclusões em relatórios à distância aqui também o poder é invulnerável.

Para Ian Shaw (2016a, p. 224-240) essa é a consolidação histórica da "vigilância de tudo", permeada pela "guerra de todos contra todos" por meio do domínio dos dados pessoais e da ecologia da vida humana (vida cotidiana), e três aspectos são os centrais dessa seguridade atmosférica: (I) a segregação urbana heterogênea por meio de esferas em redes que incorporam princípios de separação do outro por meio das tecnologias de repressão; (II) o urbanismo militar e a fortificação de fronteiras para além do Estado-Nação, como os enclaves fortificados e a cada vez mais violenta segurança privatizada; (III) a dronificação da atmosfera, ou seja, a capacidade dos drones em policiarem e petrificarem as atmosferas de segregação e hiper seguridade.

Esse cenário se aplica ao poder de vigiar, à vigilância no contexto da big data, que é uma transformação que tende a ser ampliada pela presença dos drones no dia-a-dia. Há uma interseção entre a big data e a chamada "drone data" — ou seja, entre os dados adquiridos por esse meio, de precisão sem precedentes. Esses dados podem ser meteorológicos, topográficos ou do comportamento de consumidores, sugerindo novos dilemas éticos relativos à privacidade em detrimento ao livre desenvolvimento dessa tecnologia de captação de imagens e geração de dados (FINN; DONOVAN, 2016, p. 47). Esse cenário também destaca a possibilidade desses dispositivos serem cada vez mais autônomos e gerarem dados por si e em rede - é o que a literatura tem chamado de "Internet dos Drones" ou Internet of Drone Things (IoDT), que contempla os drones efetivamente inteligentes, ou smart drones, que são conectados à internet com outros objetos e independem do total controle de um operador/piloto (NAYYAR; NGUYEN; NGUYEN, 2020).

A digitalização e a obsessão pelo vídeo também constituem a dronificação do poder, pois esse poder pode é exercido sem qualquer vulnerabilidade para a pessoa que o exerce (CHAMAYOU, 2015, p. 20) — sendo vulnerável a algum ataque, no máximo, o equipamento 
eletrônico que capta imagens e ataca à distância. A dimensão física é desprezada enquanto risco para quem exerce o poder (AMARAL, 2018, p. 91). Ocorre um processo de desumanização, no qual cada vez mais o poder se retira dos riscos e os delega a outros (os inimigos), portanto, a guerra dos drones é perpetuada de forma distante tanto pelos humanos, pelas máquinas ou pelos discursos midiáticos do medo - que justificam as práticas de agressão e controle (CHANDLER, 2020, p. 60-80).

Pollack (2018, p. 299) considera a relação entre os drones e a governança como a “normalização do impensável”: é a transformação da violência totalitária em prática da vida cotidiana, uma habituação como fenômeno político e cultural, produto de um desenvolvimento ideológico no qual o pensamento crítico é desestimulado e visto como subversivo. Dois pontos são essenciais para entender essa afirmação do autor: a objetificação dos objetos/inimigos (o que permite a disponibilidade dos corpos), e a burocratização da guerra (ao serem transformadas as decisões de morte em práticas codificadas/algorítmicas).

O primeiro ponto normalizado é o da "disponibilidade": a dronificação do poder implica a disposição assertiva de certos corpos, declarados como "morríveis". Nada mais do que um eufemismo para assassinatos, mascarados sob a forma da contenção de dito radicalismo ou terrorismo - tudo isso exercido de forma burocratizada. A tomada de decisões indireta e distante que é responsável por essas mortes ocorre no que Pollack (2018, p. 301) chama de "matrix da disponibilidade", um campo burocrático da governança norteamericana baseada em um consenso político que forma bases de dados que nada mais são do que "listas de mortes" (kill lists).

A burocratização e a dessensibilização são essenciais para o cometimento dos crimes de guerra da era dos drones, eis que há uma estrutura organizacional amoral que permite a tomada de decisões que promove a morte. A operacionalização militar é sustentada por uma rotina burocrática que absolve os culpados pela violência, justamente pelos procedimentos serem impessoais e assimilados por um sistema de guerra que ultrapassa as linhas militares ao acoplar-se à inteligência paramilitar corporativa (POLLACK, 2018, p. 305). A expansão político-comercial-militar passa pelo quadro do drone (como forma de poder e tecnologia), o que se observa nas bases norte-americanas espalhadas pelo mundo e administradas à distância - sujeitando o mundo a um imperialismo justificado pelo contraterrorismo e pela doutrina da guerra permanente (POLLACK, 2018, p. 349).

O texto de Sandbrook (2015, p. 639) avalia os impactos sociais dos drones privados/ domésticos quanto aos seguintes parâmetros: (I) segurança (justamente por se tratar de uma tecnologia que permite não expor a riscos um piloto e técnicos de imagem e vídeo); (II) 
privacidade (por causa da implicação ética da vigilância constante e da sutileza do voo dos drones); (III) bem-estar psicológico (pois a acessibilidade da tecnologia pode empoderar comunidades locais em produzir seus próprios dados mas, concomitantemente, causar o medo e a sensação de hostilidade em relação à população no solo constantes); (IV) seguridade de dados (preocupação com a coleta de dados pessoais, tanto pelos agentes de policiamento como por interesses comerciais e, além disso, porque mesmo em casos de coleta legítima, os dados estão sujeitos à ação de hackers).

Para além de uma tecnologia de guerra, mas representando o poder global, como reiterado por Saskia Sassen (2013) — “drones por lá, vigilância total por aqui” —, os drones representam, no cenário de guerra, principalmente, a burocratização da morte a um clique de distância e, no cotidiano civil, a vigilância e a extração de dados pessoais para a expansão de um mercado altamente lucrativo de dados pessoais. A aplicação dos drones no campo da segurança, por exemplo, implica a necessidade de regulação dos limites da vigilância nos aspectos da segurança do voo e da captação de dados (imagem e som). No Brasil, seu uso já vem se tornando uma prática da segurança pública, que move-se pela propulsão de um perpétuo estado de exceção justificado nas lógicas da segurança e da administração do medo (AMARAL; SALLES; MEDINA, 2019, p. 295).

A relação entre a tecnologia dos drones e a militarização é exposta na frequente interseção entre o desenvolvimento tecnológico militar e o privado, na ascensão cada vez mais de empresas militares (ESCOTO, 2017). A distinção entre os drones militares e civis não é clara, pois são tecnologias que se entrelaçam e correspondem a um novo urbanismo militar (GRAHAM, 2011), que reproduz toda a técnica militar no cotidiano urbano, formatando o espaço urbano conforme a violência das guerras e os padrões de segurança e vigilância agora privatizados. Independente da natureza do drone, o alvo da securitização é o mesmo: a população excedente (sempre considerada uma ameaça, um inimigo), sendo o drone urbano uma continuidade da permanente caça humana realizada pelos aparelhos de guerra - um espaço controlado pela ubíqua vigilância produtora de dados vinda dos céus, que Shaw (2016b) chama de dronepolis (a cidade dos drones).

A tecnologia aplicada aos drones pressupõe, também, a digitalização dos dados, por isso ocorre a interseção entre eles e o chamado big data (FINN; DONOVAN, 2016, p. 47): os drones constituem uma plataforma de captação de dados, integrada a outras tecnologias e a sistemas de gestão de dados, sendo evidentes as implicações éticas de sua utilização frente aos direitos civis. Os impactos previstos são: (I) o potencial de identificação das pessoas por meio dos dados visuais coletados, principalmente quando associados aos sistemas de dados das 
redes sociais e bancos de dados governamentais; (II) a discriminação e a desigualdade causada pela gestão desigual dos dados; ${ }^{1}$ e (III) a marginalização digital das práticas ligadas aos indivíduos ou comunidades locais, tendo em vista a onipresença das grandes corporações digitais.

O cenário da domesticação dos drones é o da "datificação" da vida, conforme Rob Kitchin (2014, p. 152), para quem ao compreender que o big data constitui uma nova forma de racionalidade para a governança e os negócios — ou seja, ele não se desenvolve de forma não ideológica; pelo contrário, é a afirmação de uma série de argumentos/discursos que naturalizam e reproduzem a gestão de dados na forma atual: não democrática e pautada pela expropriação de dados pessoais lucrativos - conforme afirma Zuboff (2019), ao declarar que a vigilância é remunerada em um mercado de dados extraídos da vida cotidiana dos cidadãos.

A ubiquidade dos algoritmos de gestão de dados reproduz formas de violência à privacidade, que muitas vezes não podem ser caracterizadas na esfera subjetiva, ou seja, no dano físico causado pela vontade de um agressor. É um caso de violência objetiva, ${ }^{2}$ ligada às estruturas sociais de opressão, pois a dronificação é uma forma de expressão do poder que expande a disponibilidade dos corpos periféricos, sendo a expropriação dos dados pessoais só uma estratégia de enriquecimento das big techs por meio da extração da mais-valia comportamental — nos termos de Zuboff (2019) — em total desprezo à privacidade dos cidadãos.

\section{Regulação dos drones e dados pessoais}

A regulação dos drones militares é muito diferente daquela dos drones civis/domésticos: na primeira, a preocupação é focada nos crimes de guerra e no desenvolvimento secreto das tecnologias; na segunda, o desenvolvimento tecnológico é aberto, amplo e comercial. Portanto, a preocupação no uso privado dos drones se divide em duas - a privacidade e a segurança, justamente pela sobreposição desses dois fatores, enquanto a tecnologia permite práticas de vigilância por vídeo mais eficazes e acessíveis, e altera os limites da privacidade e dos direitos sobre os céus, tornando nebulosa a divisão entre o espaço privado e o público (RAO; GOPI; MAIONE, 2016, p. 87). E essa já é uma preocupação verificável pelos cidadãos, como apontam as pesquisas de Chang, Chundury e

\footnotetext{
${ }^{1}$ Desigual porque corresponde à assimetria de infraestrutura e conhecimento acerca da interpretação das informações massivas, do cidadão frente às inteligências artificiais que analisam dados em tempos reais, e que são geridas pelas grandes corporações (MAYER-SCHONBERGER; CUKIER, 2013, p. 124-128).

${ }^{2}$ Esse tipo de violência é caracterizada por Zizek (2014, p. 26) como a violência sistêmica e anônima, sob a indiferença do capital.
} 
Chetty (2017, p. 6774); Wang et al. (2016); Clothier et al. (2015); e Klauser e Pedrozo (2017); que expõem o receio das pessoas em relação às suas liberdades no cenário da popularização dos drones comerciais e recreativos.

A regulação dos drones privados ainda é algo em consolidação. Kakaes (2015a, p. 2934) introduz alguns princípios por trás dessa regulação, que refletem e imbricam questões relativas aos regimes regulatórios da aviação, da privacidade e dos direitos de propriedade: (I) a mudança da relação do voo com a privacidade: algo impensado anteriormente (pois os voos de altitude relevante pouco ou nada interferem na vida no solo), com os drones, que voam a baixa altitude, seu uso interfere diretamente na "vida do solo", tanto pela capacidade de captação visual como pelo incômodo sonoro; (II) a diferenciação entre os drones recreativos e os não recreativos (comerciais, policiais e técnicos). Portanto, conforme afirma o autor, a regulação dos drones, efetivamente, depende da finalidade do seu uso. Ademais, o uso recreacional pode soar inofensivo, mas é necessário garantir que as pessoas não tenham a capacidade de exercer vigilância permanente dos outros mediante o uso recreativo e que, também, tal uso não venha a ser causar violações à privacidade e aos direitos humanos. ${ }^{3}$

Com o crescente uso privado/doméstico dos drones, sucede-se a necessidade de afirmação, consistência e previsibilidade da regulação dessa tecnologia. A proteção à liberdade de ser vigiado (a não ser de no caso de um mandado justificado) não pode se tornar obsoleta em face da ubiquidade dessa nova tecnologia, ao mesmo tempo que é preciso contemplar a integração desses veículos aéreos à prestação de serviços (REHFUSS, 2015, p. 336). Um exemplo dessa prestação de serviços é se dá na expansão do consumo online entregas rápidas de mercadorias a domicílio por drones. Trata-se de algo que parece sugerir compras eficientes - todavia, é preciso verificar as consequências desse uso, e possibilitar que as pessoas tenham acesso somente aos benefícios e oportunidades dessa tecnologia, exigindo um regime regulatório inovador que compreenda a inovação tecnológica e também os Direitos Humanos (FENWICK; KAAL; VERMEULEN, 2018, p. 154).

O atual estágio da regulação internacional dos drones se consubstancia na normatividade da "Convenção de Chicago" - Convention on International Civil Aviation de 1947; a "Convenção de Varsóvia” de 1929; a "Convenção de Roma” de 1952; a "Convenção de Haia" de 1970; a "Convenção de Tóquio" e a "Convenção de Montreal” de 1981; e as correntes normativas anexas da Organização da Aviação Civil Internacional

\footnotetext{
3 Embora até mesmo pode ser utilizado no interesse de preservação de Direitos Humanos, como relata Kakaes (2015b) de como a expansão dessa tecnologia permite mais baratos e rápidos sensoriamento dos espaços periféricos e proteção de pessoas em zonas de conflitos. Também, a possibilidade de uso para a conservação ambiental na coleta de imagens de forma rápida e barata (Sandbrook, 2015, p. 644).
} 
(ICAO) (HODGINSON; JOHNSTON, 2018, p. 34-30). É a ICAO que determina as práticas e padrões recomendáveis para a pilotagem de aeronaves remotas manuais ou automáticas.

Nos EUA consolida-se um estado da regulação em quatro pontos (HEVERLY, 2015): (I) o incentivo à indústria dos drones (que compreende os incentivos por parte do Estado em promover o desenvolvimento tecnológico para a aplicação dessa tecnologia em atividades relativas ao desenvolvimento social e econômico); (II) a regulação nos Estados federados (a liberdade local em permitir ou não certas atividades de acordo com os interesses próprios); (III) o controle do uso privado (regulação calcada no danos, ou seja, na necessidade de evitálos e de responsabilizar causadores); e (IV) a propriedade intelectual (que define a federalização desses direitos, de acordo com a competência nacional sob os ares, tornando inalienável o direito à privacidade).

Os agentes da regulação estadunidense compreendem um amplo espectro institucional, que vai desde aqueles dedicados ao campo da aviação, até aquelas que se ocupam dos direitos civis. Naquele país os drones são reconhecidos como aeronaves, tendo em vista a regulação disposta pela Federal Aviation Administration (2016) (entidade governamental responsável pelos regulamentos da aviação civil), que permite sua utilização sob os auspícios de duas regras principais: (I) é proibida a utilização de drones acima de 24,9476 quilograma, independente se for para aplicação comercial ou recreativa (sendo, em caso de uso comercial, obrigatória a certificação do piloto); (II) é obrigatório o registro federal dos drones acima de 0,249 quilogramas. Além disso, o uso recreativo é limitado a: (I) respeito a diretrizes de segurança; (II) voar sempre abaixo de 400 pés; (III) voar sempre ao alcance visual (sem binóculos); (IV) nunca voar perto de outra aeronave; (V) nunca voar perto de grupos de pessoas; (VI) nunca voar perto de serviços de segurança.

O caso da regulação dos EUA suscita a reflexão sobre a necessidade de regulação federal dos drones baseada em direitos fundamentais. Takahashi (2015) salienta a possibilidade da declaração de direitos da Constituição estadunidense garantir a inviolabilidade da privacidade do cidadão frente à vigilância por drones (quarta emenda) e a impossibilidade de auto incriminação sem haver a necessidade comprovada e esclarecida de testemunho (quinta emenda). Ou seja, é preciso garantir o não-exercício jurídico dos dados obtidos pela vigilância ubíqua dos drones: ou seja, o fato de essa tecnologia permitir vigilância por vídeo fácil e barata não pode levar à sua simples normalização.

$\mathrm{Na}$ União Europeia, sendo os drones também considerados aeronaves, os paradigmas normativos de aviação são regulados pela European Aviation Safety Agency (EASA). Tais normas consideram todas as partes envolvidas na atuação dos drones (CAMPOS, 2018, p. 
37): os fabricantes de drones, os operadores (sempre licenciados), os pilotos (não licenciados em uso recreativo e com drones abaixo do peso determinado), público geral (afetados pela preocupação com a segurança dos voos) e a economia (os negócios que se utilizam dessa tecnologia para serviços inovadores). A definição de drone é, para os fins da regulação, pura e simplesmente, de uma aeronave sem piloto a bordo — sendo divididas entre as categorias: aberta (risco baixo, os drones de uso interno), de operação específica (médio risco, em que um manual de operação é requerido), e certificado (alto risco, em que é obrigatória a licença, a manutenção e o treinamento).

Quanto aos direitos civis afetados pelos drones, a União Europeia compreende a coleta de dados via drones (de calor, imagens e som) para fins de segurança pública, com justificado interesse — sendo aplicável a legislação de proteção aos dados e privacidade (VOSS, 2014, p. 175). Entretanto, uma preocupação relevante quanto à regulação europeia é trazida por Lavalle (2019, p.4), que afirma haver uma tendência à massificação do uso dos drones civis, bem como a necessidade de participação política dos cidadãos — tanto na deliberação sobre as regras quanto na preparação para a nova realidade. Nesse sentido, Pauner et al. (2015) criticam o modelo regulatório atual da União Europeia e propõem a maior estandardização dos princípios de proteção de dados e da privacidade — ou seja, uma maior intervenção estatal e responsabilização dos agentes privados desenvolvedores dessas tecnologias por meio da mitigação de riscos e dos compliances próprios.

Quanto aos dados pessoais, o regulamento geral sobre a proteção de dados - General Data Protection Regulation (GDPR) — da União Europeia estabelece um regime de proteção dos dados pessoais, exigindo que os controladores de dados esclareçam abertamente quais são as formas de captação (transparência) e de armazenamento de dados, e a exigência de que estas devem ser compatíveis com a atividade que resultou no consentimento livre e informado dos usuários. Portanto, o atual estado da regulação dos drones na UE exige a adequação à proteção dos dados, como é o modelo desenvolvido por Bassi et al. (2019, p. 17) ao promover um algoritmo de navegabilidade por um sistema que respeite áreas consideradas privadas e de captar dados particulares - que é um modelo de privacidade pelo design, pois o respeito ao direito à privacidade está incorporado na própria programação do drone.

No Brasil, a regulação aérea é exercida por diversos órgãos competentes. A Instrução do Comando da Aeronáutica (ICA) 100-40 de 2015 (vigente desde 2019), intitulada "sistemas de aeronaves remotamente pilotadas e o acesso ao espaço aéreo brasileiro", edita a nomenclatura e as questões técnicas desse tipo de aeronave. Ela aborda os paradigmas propriamente técnicos do registro e da licença, as regras de acesso de espaço aéreo e a 
segurança operacional. Todavia, ela também aborda as seguintes questões legais, que são fiscalizadas pela $\mathrm{ANAC}^{4}$ : (a) seguro (os operadores devem possuir seguro contra terceiros); (b) imputação de responsabilidade (a responsabilidade é do operador); (c) infrações (contravenções ou crimes) ${ }^{5}$ (d) respeito aos direitos individuais (a obrigação de respeito aos direitos de terceiros, como a privacidade e a imagem das pessoas); e (e) transporte de artigos perigosos (em regra, proibido, sendo exigida, para eventuais exceções, prévia autorização da ANAC).

Essa instrução caracteriza uma preocupação de colocar o Brasil no mesmo patamar regulatório e normativo mundial nos drones de uso civil, demonstrando ser uma regulação que alia a preocupação técnica da aviação e dos procedimentos com os direitos individuais e ambientais (SPADOTTO, 2016, p. 625-626). O conceito de responsabilidade sob o uso dos drones imputa implicações com a Lei de Crimes Ambientais e o Estatuto da Cidade quanto à afetação de direitos difusos, como por exemplo, o âmbito civil na agressão à privacidade e à imagem pessoal. O caminho indicado por essa instrução aprimora as normas puramente técnicas, desconectadas dos direitos individuais (PRIEBE; PETRY, 2018, p. 39), trazendo à tona as relevantes implicações sociais e ambientais.

A preocupação para com os dados, embora atinja diretamente direitos constitucionais, só ganhou uma plataforma normativa no Brasil com a Lei Geral de Proteção de Dados (LGPD) de 2019. Essa lei sustenta os fundamentos da proteção de dados tanto no respeito à privacidade quanto no desenvolvimento tecnológico (art. $2^{\circ}$, I e V). Também atenta para os princípios da responsabilidade do controlador ou operador de dados pessoais — sendo as atividades de tratamento de dados orientadas pelo princípio da responsabilização e da prestação de contas (art. 6, X), e os procedimentos da gestão dos dados sujeitos à auditoria (art. $20, \S 2^{\circ}$ ), indicando sua adequação à noção de accountability.

$\mathrm{Na}$ expansão das aplicações do drones, e em razão da sua capacidade de coletar dados, principalmente porque aliados a sistemas de corporações digitais transnacionais de influência global, essa tendência regulatória da União Europeia e do Brasil, em compreender que é preciso exigir o respeito à proteção dos dados e à privacidade no desenvolvimento tecnológico, justamente por eles seguirem padrões internacionais e uma ordem normativa

\footnotetext{
${ }^{4}$ A Agência Nacional de Aviação Civil (ANAC) por meio do Regulamento Brasileiro da Aviação Civil Especial (RBAC-E) $\mathrm{n}^{\circ} 94$ aborda os requisitos gerais de competência da ANAC relativos à segurança desses vôos.

${ }^{5}$ Conforme o texto da ICA 100-40/2015: a) Art. 33 do Decreto Lei ${ }^{\circ} 3.688$ (Lei das Contravenções Penais) - Dirigir aeronave sem estar devidamente licenciado; b) Art. 35 do Decreto Lei $n^{\circ} 3.688$ - Entregar-se na prática da aviação fora da zona em que a lei o permite, ou fazer descer a aeronave fora dos lugares destinados a esse fim; c) Art. 132 do Decreto Lei $n^{\circ} 2.848$ (Código Penal) - Expor a vida ou a saúde de outrem a perigo direto e iminente; e d) Art. 261 do Decreto Lei $n^{\circ}$ 2.848 - Expor a perigo aeronave, própria ou alheia, ou praticar qualquer ato tendente a impedir ou dificultar navegação aérea.
} 
própria, pode permitir uma regulação mais eficiente, para além do regime regulatório proibitivo. Essa responsabilidade social empresarial é a resposta adequada ao contexto jurídico contemporâneo no qual essas grandes empresas cada vez mais estabelecem normas de conduta próprias ou representativas de seus modelos de negócios (um subsistema próprio), no qual a regulação estatal positivista não contém a autorregulação (FORNASIER; FERREIRA, 2015, p. 409-411).

A dronificação da guerra e a distância dos atos de governo constituem os frequentes crimes de guerra e contra a humanidade por parte dos EUA, constantemente patrocinador da prática de "rendição forçada" - ocultando violências e dispondo de corpos em nome de seus interesses. Essas práticas comprovam o desinteresse do poder com práticas alinhadas aos Direitos Humanos, por isso Wali Aslam (2013, p. 97-116) sugere que frente ao poder constituído dos EUA nas relações geopolíticas é preciso constituir, sob a premissa de uma sociedade mundial, uma responsabilidade sob o poder. Em analogia, para fora do ambiente das guerras, a tecnologia dos drones como promotor da vigilância também está associada a um poder claro, o das big techs que desenvolvem e se utilizam das práticas associadas ao controle das imagens adquiridas de cima para baixo, literalmente.

A aproximação à regulação precisa ser feita de acordo com as inovações tecnológicas, e compreender a capacidade que a regulação by design possui em assimilar as inovações, mas se adequar também à dinâmica da sociedade e do Estado baseada em princípios de Direitos Humanos, salientando-se aqui a defesa da privacidade e da integridade pessoal. É o Direito como metatecnologia, conforme preceitua Magrani (2019, p. 261), que é o regime regulatório no qual o desenvolvimento da tecnologia ocorre aparelhado por valores jurídicos — ou seja, o próprio desenvolvimento pelos engenheiros precisa respeitar a importância dos elementos democráticos que elaboraram direitos e se estabelecem na esfera pública. É um movimento de que ao mesmo tempo privatiza responsabilidade e regulação para o ente privado e publiciza os princípios do desenvolvimento tecnológico.

Mais do que prever limitações legais ao uso dos drones, é preciso conceber formas de auditabilidade social por meio de accountability algorítmico dessa tecnologia — ou seja, a auditabilidade como dimensão regulatória exigindo o direito à privacidade no âmbito algorítmico (SOMBRA, 2019, p. 186). A forma pela qual ela funciona e é aplicada, e como ela interfere na vida social, não podem ser normalizadas sem uma auditabilidade ativa por meio da sociedade, para além do mero consentimento (o qual é ligado ao conceito de consumidor, não de cidadão). A programação dos drones deve ser integrada com os usuários, esclarecendo as suas atividades, como processa dados ou os armazena - de forma clara e 
com linguagem acessível (VEDDER; NAUDTS, 2017, p. 214). Esse é o regime regulatório indicado frente ao cenário das big techs e à privatização das tecnologias de guerra.

Esse fenômeno consolida a tecnologia algorítmica como um campo de análise transdisciplinar do ponto de vista epistemológico (KITCHIN, 2017, p. 26-27), sendo necessária uma abordagem crítica ao ponto de influenciar a responsabilidade social dos desenvolvedores. Se nas guerras é preciso retomar que a morte por comando, a longa distância e operacionalmente secreta é uma uma tirania, uma espécie absoluta e opressiva de poder e é preciso deixar de ser indiferente a isso (POLLACK, 2018, p. 299); na dronificação doméstica, é preciso enfrentar as violências à privacidade e os direitos fundamentais e suas garantias - normalizadas frente ao desenvolvimento e acessibilidade das imagens obtidas via drone.

\section{Conclusão}

$\mathrm{Na}$ presente pesquisa estudou-se a regulação dos drones sob o contexto teórico da dronificação do poder. Seu primeiro objetivo específico foi contextualizar tal dronificação, tendo sido possível identificar a associação do seu desenvolvimento tecnológico e de sua ideologia militar com o ambiente urbano e o uso doméstico. Neste ponto, foi possível concluir que a dronificação é uma forma de expressão do poder capaz de expandir a disponibilidade dos corpos periféricos, se demonstrando como uma forma de apropriação de dados sociais com alto grau de indiferença no que tange à privacidade. Tais tecnologias fazem parte atualmente do cotidiano dos cidadãos, tendo aplicações variadas, mas que, aliadas ao desenvolvimento militar se traduzem em formas de exercício do poder - aquele capaz de vigiar e até mesmo se demonstrar indiferente a mortes sob forma do exercício do poder global, visando o lucro a partir da expropriação de dados gerados. Logo, à multiplicidade de destinações que envolvem os drones domésticos correspondem o seu papel na sociedade informacional; sendo assim, ocorre a transformação da violência totalitária em práticas da vivência cotidiana.

O segundo objetivo específico deste trabalho foi confrontar a literatura da dronificação do poder com a realidade da regulação, buscando (des)continuidades frente a um novo paradigma regulatório. Nesse sentido, apesar de não se poder apontar diretamente para nenhuma via regulatória ideal, tem-se que a disciplina adequada acerca do assunto tem de abranger o poder das corporações informacionais que estão por trás do desenvolvimento de tais tecnologias. E por fim, que os drones civis atrelados ao cotidiano da sociedade 
contemporânea resultam da privatização das ideologias de guerra. Assim, se tornam necessárias alternativas que visem ao estabelecimento de práticas regulatórias que estejam em consonância com a proteção de dados e da privacidade nos algoritmos presentes em tais sistemas.

A reflexão teórica trazida por essa pesquisa é de crítica ao regime regulatório tradicional frente aos drones mas, ao mesmo tempo, aponta para o valor de algumas iniciativas já consolidadas. A regulação baseada na divisão entre técnica da aviação e os direitos civis ou ambientais está defasada frente à ubiquidade do tratamento de dados pessoais digitais - a chamada big data —, justamente porque os drones possuem uma enorme capacidade técnica de coleta de dados (imagens, sons, calor, mapeamento, entre outros) e, ainda mais, no contexto da conexão com a internet, os drones conseguem operar autonomamente e analisar dados corroborados com os produzidos por outros objetos, tudo isso em tempo real.

Portanto, o regime regulatório adequado para os drones deve ser capaz de regular o poder das corporações informacionais que desenvolvem essas tecnologias, mas não de modo meramente proibitivo - pois a regulação estatal não alcança as normatizações estabelecidas globalmente pelos paradigmas de programação desses desenvolvedores. Os drones domésticos/civis nada mais são que um resultado da privatização de ideologias de guerra, sintomas da dronificação do poder - exercido a distância e sem assumir riscos. Dessa forma, a auditabilidade social é uma alternativa para que as empresas desenvolvam práticas que respeitem os princípios de proteção de dados e da privacidade no núcleo algorítmico desses sistemas - tendo em vista que a regulação posterior (proibitiva) sempre rema contra a correnteza exercida pelas big techs.

\section{Referências}

AMARAL, Augusto Jobim. Biopolítica e Biocapitalismo: implicações da violência do controle. In: SABARIEGO, Jesús; MATOS, Ana Raquel (org.). Democracia e Direitos Humanos na Era Digital. Coimbra: CES - Universidade de Coimbra, 2018, p. 81-99.

AMARAL, Augusto Jobim do; SALLES, Eduardo Baldissera Carvalho; DA SILVA MEDINA, Roberta. Urbanização Militarizada e Controle Social: primeiras impressões sobre os "drones" como dispositivos de segurança pública no Brasil. Revista de Direito da Cidade, v. 11, n. 2, p. 278-298, 2019.

\section{ASLAM, Wali. The United States and Great Power Responsibility in International}

Society: Drones, rendition and invasion. Oxford: Routledge, 2013. 
BASSI, Eleonora; BLOISE, Nicoletta; DIRUTIGLIANO, Jacopo; FICI, Gian Piero; PAGALLO; PRIMATESTA, Stefano; QUAGLIOTTI, Fulvia. The Design of GDPR-Abiding Drones Through Flight Operation Maps: A Win-Win Approach to Data Protection, Aerospace Engineering, and Risk Management. Minds and Machines, v. 29, n. 4, p. 579-601, 2019.

BRASIL. Agência Nacional de Aviação Civil. RBAC-E 94. 2017. Disponível em: https://www.anac.gov.br/assuntos/legislacao/legislacao-1/rbha-e-rbac/rbac/rbac-e-94. Acesso em: 15 mar 2020.

BRASIL. Ministério da Defesa. Comando da Aeronáutica. Departamento de Controle do Espaço Aéreo. ICA 100-40 (Sistemas de aeronaves remotamente pilotadas e o acesso ao espaço aéreo brasileiro. 2015. Disponível em: https://www.decea.gov.br/static/uploads/2015/12/Instrucao-do-Comando-da-AeronauticaICA-100-40.pdf. Acesso em: 15 mar 2020.

BRASIL. Lei no 13.709, de 14 de agosto de 2018. Lei Geral de Proteção de Dados. Disponível em: http://www.planalto.gov.br/ccivil_03/_ato2015-2018/2018/lei/L13709.htm. Acesso em: 15 mar 2020.

CHAMAYOU, Grégoire. Teoria do drone. Trad. Célia Euvaldo. São Paulo: Cosac Naify, 2015.

CHANDLER, Katherine. Unmanning: How Humans, Machines and Media Perform Drone Warfare. New Brunswick, Camden; Newark, New Jersey; London: Rutgers University Press, 2020. DOI:https://doi.org/10.2307/j.ctvxhrhv4.

CHANG, Victoria; CHUNDURY, Pramod; CHETTY, Marshini. Spiders in the sky: User perceptions of drones, privacy, and security. In: MARK, Gloria; FUSSEL, Susan (orgs.). Proceedings of the 2017 CHI conference on human factors in computing systems 2017. New York: Association for Computing Machinery, 2017, p. 6765-6776. Disponível em: https://dl.acm.org/doi/abs/10.1145/3025453.3025632. Acesso em: 15 mar 2020.

CLOTHIER, Reece A.; GREER, Dominique A.; GREER, Duncan G.; MEHTA, Amisha M. Risk perception and the public acceptance of drones. Risk analysis, v. 35, n. 6, p. 1167-1183, 2015. DOI: https://doi.org/10.1111/risa.12330.

COSTA, Leonardo da Costa Priebe da; PETRY, Alexandre. Big Brother Is Watching You: Uma Análise Da Regulação Brasileira Sobre Drones No Tocante À Violação Da Privacidade. Justiça \& Sociedade - Revista do Curso de Direito do IPA, v. 3, n. 1, p. 9-44, 2018. DOI: http://dx.doi.org/10.15602/2525-3883/rjs.v3n1p9-44.

DILANIAN, Ken; KUBE, Courtney. Airport informants overhead drones: How the U.S killed Soleimani. NBC News, 10 jan 2020. Disponível em: https://www.nbcnews.com/news/mideast/airport-informants-overhead-drones-how-u-s-killedsoleimani-n1113726. Acesso em: 18 mar 2020.

DOUCET, Lyse. Qasem Soleimani: US kills top Iranian general in Baghdad air strike. BBC News, 03 jan 2020. Disponível em: https://www.bbc.com/news/world-middle-east-50979463. Acesso em: 18 mar 2020. 
ESCOTO, Roberto. A inserção das empresas militares e de segurança privada na indústria de defesa do Brasil. Doutrina Militar Terrestre em Revista, v. 5, n. 11, p. 6-13, 2017.

FEDERAL AVIATION ADMINISTRATION. Educational Users. Disponível em: https://www.faa.gov/uas/educational_users/. Acesso em: 15 mar 2020.

FELTEN, Maria Cláudia. Os Direitos Fundamentais e as Tecnologias da Comunicação e Informação: Grupos de Trabalho do WhatsApp. Revista Thesis Juris, v. 6, n. 1, p. 120-144, 2017. DOI: https://doi.org/10.5585/rtj.v6i1.589

FENWICK, Mark; KAAL, Wulf; VERMEULEN, Erik. Regulation Tomorrow: Strategies for Regulating New Technologies. in: KONO, Toshyuki; REICH, Arie; HISCOCK, Mary (org.). Transnational Commercial and Consumer Law: Current Trends in International Business Law. Singapore: Springer, 2018, p. 153-174.

FINN, Rachel; DONOVAN, Anna. Big data, drone data: privacy and ethical impacts of the intersection between big data and civil drone deployments. In: CUSTERS, Bart (org.). The Future of Drone Use: opportunities and Threats from Ethical and legal perspectives. Hague: Asser Press; Springer, 2016, p. 47-67.

FORNASIER, Mateus de Oliveira; FERREIRA, Luciano Vaz. A regulação das empresas transnacionais entre ordens jurídicas estatais e não estatais. Revista de Direito Internacional, v. 12, n. 1, 2015.

GRAHAM, Stephen. Cities under siege: the new military urbanism. Londres; Nova Iorque: Verso, 2011.

G1. Drone que matou líder iraniano é o mais letal da frota dos EUA. G1, jan 2020. Disponível em: https://g1.globo.com/mundo/noticia/2020/01/04/drone-que-matou-lideriraniano-e-o-mais-letal-da-frota-dos-eua.ghtml. Acesso em: 18 mar 2020.

HEVERLY, Robert A. The state of drones: state authority to regulate drones. Albany Governmet Law Review, v. 8, p. 29, 2015. Disponível em: https://heinonline.org/HOL/LandingPage?handle=hein.journals/aglr8\&div=8\&id=\&page=. Acesso em: 15 mar 2020.

KAKAES, Konstantin. Drone Regulation and the protection of Human Rights. In: NEW AMERICA. Drones and aerial observation: new technologies for property rights, human rights, and global development - a primer. New America, 2015b. Disponível em: http://drones.newamerica.org/primer/Chapter\%208.pdf. Acesso em: 15 mar 2020.

KAKAES, Konstantin. Drone Regulation - Privacy and Property Rights. In: NEW AMERICA. Drones and aerial observation: new technologies for property rights, human rights, and global development - a primer. New America, 2015a. Disponível em: http://drones.newamerica.org/primer/Chapter\%203.pdf. Acesso em: 15 mar 2020.

KIM, Kye Won; SEO, Jin Seok. Study on Legal Regulations for Utilization of Drone in Private Security. Convergence Security Journal, v. 17, n. 5, p. 163-178, 2017. 
KITCHIN, Rob. Thinking critically about and researching algorithms. Information, communication \& Society, v. 20, n.1, 2017. DOI:

https://doi.org/10.1080/1369118X.2016.1154087.

KLAUSER, Francisco; PEDROZO, Silvana. Big data from the sky: popular perceptions of private drones in Switzerland. Geographica Helvetica, v. 72, n. 2, p. 231-239, 2017.

LAVALLÉE, Chantal. The EU policy for civil drones: the challenge of governing emerging technologies. Institute for European Studies Policy Brief, n. 1, 2019. Disponível em: http://aei.pitt.edu/97399/. Acesso em: 15 mar 2020.

MACHADO, Ronny Max; FUJITA, Jorge Shiguemitsu. Os impactos da sociedade da informação no direito à privacidade da pessoa natural e da pessoa jurídica. Revista Thesis Juris, v. 7, n. 2, p. 258-278, 2018. DOI: https://doi.org/10.5585/rtj.v7i2.605.

MAGRANI, Eduardo. Entre Dados e Robôs: A Ética Das "Coisas": Da Ética Do Discurso E Racionalidade Comunicativa Ao Novo Materialismo De Sistemas Sociotécnicos. 2 ed. Porto Alegre: Arquipélago, 2019.

MAYER-SCHONBERGER, Vyktor; CUKIER, Kenneth. Big Data: a revolution that will transform how we live, work, and think. Boston; New York: Houghton Mifflin Harcourt, 2013.

MIGUEL MOLINA, Blanca de; SEGARRA ÕNA, Marival. The Drone Sector in Europe. In: MIGUEL MOLINA, María; SANTAMARINA CAMPOS, Virgínia (Orgs.). Ethics and Civil Drones: European Policies and Proposals for the Industry. New York: Springer, 2018, p. 734.

NAYYAR, A., NGUYEN, BL., NGUYEN, N.G. The Internet of Drone Things (IoDT): Future Envision of Smart Drones. In: LUHACH, A., KOSA, J., POONIA, R., GAO, XZ., SINGH, D. (eds). First International Conference on Sustainable Technologies for Computational Intelligence: Advances in Intelligent Systems and Computing, v. 1045. Singapore: Springer, 2020, p. 563-580.

PAUNER, Cristina; KAMARA, Irene; VIGURI, Jorge. Drones. Current challenges and standardisation solutions in the field of privacy and data protection. In: 2015 ITU Kaleidoscope: Trust in the Information Society (K-2015). IEEE, 2015, p. 1-7. Disponível em: https://ieeexplore.ieee.org/abstract/document/7383633/. Acesso em: 15 mar 2020.

POLLACK, Norman. Capitalism, Hegemony and Violence in the Age of Drones. Basingstoke: Palgrave MacMillan, 2018.

RAJ, Rahul; KAR, Soumyashree; NANDAN, Rohit; JAGARLAPUDI, Adinarayana. Precision Agriculture and Unmanned Aerial Vehicles (UAVs). In: AVTAR, Ram; WATANABE, Teiji (org.). Unmanned Aerial Vehicle: Applications in Agriculture and Environment. Cham: Springer, 2020, p. 7-23.

REHFUSS, Abigail. The domestic use of drones and the fourth amendment. Albany Government Law Review, v. 8, p. 313-336, 2015. 
SANDBROOK, Chris. The social implications of using drones for biodiversity conservation. Ambio, v. 44, n. 4, p. 636-647, 2015.

SANTAMARINA CAMPOS, Virgínia. European Union Policies and Civil Drones. In: MIGUEL MOLINA, María de; SANTAMARINA CAMPOS, Virgínia (eds.). Ethics and Civil Drones: European Policies and Proposals for the Industry. Nova Iorque: Springer, 2018.

SANTOS, Boaventura de Sousa. Apresentação. In: SANTOS, Boaventura de Sousa; MENDES, José Manuel. Demodiversidade - Imaginar novas possibilidades democráticas. Belo Horizonte: Autêntica, 2018.

SASSEN, Saskia. Drones over there, total surveillance over here. Al Jazeera. Disponível em: https://www.aljazeera.com/indepth/opinion/2013/02/2013210114231346318.html. Acesso em: 01 mar 2020.

SHAW, Ian. Predator Empire: Drone Warfare and Full Spectrum Dominance. Minneapolis; Londres: University of Minnesota Press, 2016a.

SHAW, Ian. The urbanization of drone warfare: Policing surplus populations in the dronepolis. Geographica Helvetica, v. 71, n. 1, p. 19-28, 2016b. Disponível em: https://eprints.gla.ac.uk/110472/. Acesso em 15 mar 2020.

SOMBRA, Thiago Luís Santos. Direito à privacidade e proteção de dados no ciberespaço: a accountability como fundamento da Lex Privacy. 2019. 219 f. Tese (doutorado em Direito) - Universidade de Brasília, Brasília, 2019. Disponível em: https://repositorio.unb.br/handle/10482/35752. Acesso em 20 fev 2020.

TAKAHASHI, Timothy T. The Rise of the Drones: The Need for Comprehensive Federal Regulation of Robot Aircraft. Albany Government Law Review, v. 8, p. 63, 2015.

ULMER, Marlin W.; THOMAS, Barrett W. Same-day delivery with heterogeneous fleets of drones and vehicles. Networks, v. 72, n. 4, p. 475-505, 2018.

UNIÃO EUROPEIA. General Data Protection Regulation 2016. Disponível em: https://gdpr-info.eu/. Acesso em: 15 mar 2020.

VEDDER, Anton; NAUDTS, Laurens. Accountability for the use of algorithms in a big data environment. International Review of Law, Computers \& Technology, v. 31, n. 2, p. 206224, 2017. DOI: https://doi.org/10.1080/13600869.2017.1298547

VERMEIREN, Vadim; VAN DE VELVE, Samuel; BOES, Michiel; VAN WIJMEERSCH, Jan-Frederik. How a cutting-edge technology can benefit the creative industries: the positioning system at work. in: SANTAMARINA CAMPOS, Virginia; SEGARRA ONA, Mariva. Drones and the creative industry. New York: Springer, 2018, p. 115-128.

VOSS, W. Gregory. Privacy law implication of the use of drones for security and justice purposes. International Journal of Liability and Scientific Enquiry, v. 6, n. 4, p. 171-191, 2014. DOI: 10.1504/IJLSE.2013.060848. 
WANG, Yang; XIA, Huichuan; YAO, Yaxing; HUANG, Yun. Flying eyes and hidden controllers: A qualitative study of people's privacy perceptions of civilian drones in the US.

Proceedings on Privacy Enhancing Technologies, v. 2016, n. 3, p. 172-190, 2016.

Disponível em:https://www.degruyter.com/dg/viewarticle/j\$002fpopets.2016.2016.issue3\$002fpopets-2016-0022\$002fpopets-2016-0022.xml. Acesso em: 15/03/2020.

ZIZEK, Slavoj. Violência. Trad. Miguel Serras Pereira. São Paulo: Boitempo, 2014.

ZUBOFF, Shoshana. The age of surveillance capitalism: The fight for a human future at the new frontier of power. London: Profile Books, 2019. 